\title{
Nucleation and growth of tin in Pb-free solder joints
}

\author{
C.M. Gourlay ${ }^{1 *}$, S.A. Belyakov ${ }^{1}$, Z.L. Ma ${ }^{1}$, J.W. Xian ${ }^{1}$ \\ ${ }^{1}$ Department of Materials, Imperial College, London. SW7 2AZ. UK \\ *c.gourlay@imperial.ac.uk
}

\section{$0 \quad$ Abstract}

The solidification of Pb-free solder joints is overviewed with a focus on the formation of the $\beta S n$ grain structure and grain orientations. Three solders commonly used in electronics manufacturing, Sn-3Ag$0.5 \mathrm{Cu}, \mathrm{Sn}-3.5 \mathrm{Ag}$ and $\mathrm{Sn}-0.7 \mathrm{Cu}-0.05 \mathrm{Ni}$, are used as case studies to demonstrate that growth competition between primary dendrites and eutectic fronts during growth in undercooled melts is important in $\mathrm{Pb}$-free solders, and that a metastable eutectic containing $\mathrm{NiSn}_{4}$ forms in $\mathrm{Sn}-3.5 \mathrm{Ag} / \mathrm{Ni}$ joints. Additionally, it is shown that the substrate (metallization) has a strong influence on the nucleation and growth of tin. We identify Co, Pd and Pt substrates as having potential to control solidification and microstructure formation. In the case of $\mathrm{Pd}$ and Pt substrates, $\beta \mathrm{Sn}$ is shown to nucleate on the $\mathrm{PtSn}_{4}$ or $\mathrm{PdSn} \mathrm{I}_{4} \mathrm{IMC}$ reaction layer at relatively low undercooling of $\sim 4 \mathrm{~K}$, even for small solder ball diameters down to $<200 \mu \mathrm{m}$.

\section{$1 \quad$ Introduction}

The transition to $\mathrm{Pb}$-free electronic interconnections has been underway for more than a decade and despite the exemptions to the RoHS Directive there are few applications where Pb-free solders are not being used. At the same time, electronic packaging technologies have been advancing and there is an ongoing need to develop next-generation $\mathrm{Pb}$-free solders and substrates that are better suited to smaller joints that can operate at higher temperature and that are more reliable.

The most commonly used $\mathrm{Pb}$-free solders are hypoeutectic or near-eutectic compositions from the Sn-Ag-Cu (SAC), Sn-Ag or Sn-Cu-Ni alloy systems. These compositions solidify with significant differences to the near-eutectic $\mathrm{Sn}-\mathrm{Pb}$ solders used previously. For example, where the $\mathrm{Sn}-37 \mathrm{~Pb}$ 
eutectic solidifies as a 66:34 vol\% mixture of two nonfaceted phases, the common Pb-free solders have eutectic points (and grooves etc.) at high Sn content and form eutectic mixtures containing at least 95 vol\% $\beta$ Sn phase and $<5$ vol\% of faceted intermetallic compounds (IMCs). In addition to the much higher volume fraction of $\beta S n$, the presence of faceted phases has a strong influence on the kinetics of solidification and on the competition between the growth of $\beta$ Sn dendrites vs $\beta$ Sn-IMC eutectic vs. primary IMC at different levels of undercooling [1-3]. In this sense, there are parallels between $\mathrm{Pb}$-free solder solidification and that of the nonfaceted-faceted eutectics used in structural castings such as Al-Si [4] and Fe-C [5]. However, a significant difference is that the mass of solder in an electronic interconnection is typically on the order of $10^{\circ}-10^{-6} \mathrm{mg}$ (diameter $\sim 760-10 \mu \mathrm{m}$ ) which leads to small-sample effects, such as the development of large melt undercoolings, similar to droplet investigations in the study of rapid solidification (e.g. [6]). A further difference is that soldering dissolves some of the substrate and reacts with it. This has two effects: first, partial substrate dissolution significantly changes the liquid composition away from the original solder composition; and second, $\beta$ Sn nucleation occurs in a liquid contacting an IMC reaction layer. These latter two effects will be discussed further throughout this paper.

It has been widely reported that the solidification of $\mathrm{Pb}$-free solder joints usually involves a large and variable nucleation undercooling for $\beta$ Sn [7-10] and generates only a small number ( 1-6) of $\beta$ Sn grains in each joint that are often twinned and have variable orientation relative to the joint geometry $[9,11-14]$. The large nucleation undercooling for tin permits primary intermetallic compounds (IMCs) to form if the temperature falls below an IMC liquidus line/surface before tin nucleation $[12,15,16]$. A larger undercooling also decreases the length scale of the $\beta$ Sn dendrites and eutectic mixture(s), and encourages interlaced $\beta$ Sn dendrite growth in Sn-Ag-Cu solders $[9,14]$. In this sense, a large nucleation undercooling for tin might be preferable as it reduces the eutectic IMC particle size, generates a small interphase spacing and produces many $\beta S n$ grain boundaries from interlaced dendrites even though the number of $\beta S n$ grains is small. However, there are also 
significant reliability issues associated with a small number of $\beta S n$ grains with random orientation relative to the joint [17]. A joint containing few $\beta$ Sn orientations will have highly anisotropic properties because $\beta S n$ has highly directional thermophysical properties [18]. For example, the coefficient of thermal expansion [19], elastic stiffness [20], diffusion coefficient of common solutes [21] and plasticity [17] are all strongly direction dependent in $\beta$ Sn. Furthermore, if the few $\beta$ Sn grains are oriented differently in each joint, then the behaviour of each joint is unique. For example, electromigration has been shown to be worst when the [001] is aligned with current flow [22] and, thus, the electromigration kinetics are different in each joint [23]. Therefore, there is a need to better understand the factors affecting the development of $\beta S n$ grains during solidification and to develop ways to control the $\beta S n$ grain size and/or orientation(s) in solder joints.

Most detailed work on the nucleation and growth of tin in $\mathrm{Pb}$-free solders has been conducted on $\mathrm{Sn}-\mathrm{Ag}-\mathrm{Cu}, \mathrm{Sn}-\mathrm{Ag}$ and $\mathrm{Sn-Cu}$ alloys. Much of our work has been on $\mathrm{Sn}-0.7 \mathrm{Cu}-0.05 \mathrm{Ni}$ solder, commonly known as SN100C. Sn-0.7Cu-0.05Ni has been used since 1999 in applications that benefit from its higher 'Ragone fluidity' [24, 25], stabilised hexagonal ( $\mathrm{Cu}, \mathrm{Ni})_{6} \mathrm{Sn}_{5}$ [26], higher compliance [27] and higher impact strength [28] compared with high-silver SAC solders. The $0.05 \mathrm{wt} \% \mathrm{Ni}$ addition is significant with respect to the Sn-Cu-Ni phase diagram $[29,30]$ and produces a slightly hypereutectic composition [31] which leads to reduced Cu substrate dissolution $[27,32,33]$, dopes the $\mathrm{Cu}_{6} \mathrm{Sn}_{5}$ with $\mathrm{Ni}[26,31]$ and significantly alters the solidification sequence [3] compared with Sn-0.7Cu.

In this paper, we begin by overviewing the solidification of freestanding solder balls with a focus on comparing the widely-studied Sn-3Ag-0.5Cu (SAC305) and Sn-3.5Ag solders with Sn-0.7Cu0.05Ni solder. We next examine how solidification differs when solder balls solidify during soldering on common substrates and, finally, we explore the potential of using an IMC reaction layer to control the nucleation and growth of tin.

\section{$2 \quad$ Methods}


Solder balls were made from commercial or laboratory made solder ingots that were rolled to foil, punched into discs and then remelted to form near-spheres due to surface tension. Substrates were masked using lithography, producing circular pads $500 \mu \mathrm{m}$ in diameter. Solder balls were placed on the $\mathrm{Cu}$ or Ni substrates, fluxed with RM-5 flux and were then reflowed through a LFR400HTX TORNADO reflow oven (Surface Mount Technology, Isle of Wight, UK). The thermal profile involved heating at $\sim 2 \mathrm{~K} / \mathrm{s}$ to a peak temperature of $250^{\circ} \mathrm{C}$ followed by $\sim 50$ seconds above the eutectic temperature ( 216, 220 and $227^{\circ} \mathrm{C}$ for SAC305, Sn-3.5Ag and SN100C respectively).

For soldering of $99.9 \% \mathrm{Sn}$ to $99.9 \%$ metal substrates, Sn preforms and $\mathrm{Cu}, \mathrm{Ni}, \mathrm{Fe}, \mathrm{Co}, \mathrm{Ir}, \mathrm{Ni}, \mathrm{Pd}$, $\mathrm{Pt}, \mathrm{Au}, \mathrm{Ag}$ and $\mathrm{Cu}$ substrates were produced by rolling to $100 \mu \mathrm{m}$ sheet (for $\mathrm{Sn}$ ) or $500 \mu \mathrm{m}$ sheet (for substrates) and cutting to $3.5 \times 3.5 \mathrm{~mm}$. Each was cleaned in $\mathrm{HCl}$, covered with flux and then samples were given an initial reflow on a hot plate at $260^{\circ} \mathrm{C}$ for a short time until substrate wetting occurred.

For all joints, flux residues were removed in ethanol in an ultrasonic bath and the pre-soldered joints were placed in aluminium DSC pans (substrate side down) for further reflows in a DSC. Freestanding solder balls were placed in $\mathrm{Al}_{2} \mathrm{O}_{3}$ DSC pans. A Mettler Toledo 822 DSC was used under a $\mathrm{N}_{2}$ atmosphere with a heating rate of $10 \mathrm{~K} / \mathrm{min}$, a maximum temperature of $240^{\circ} \mathrm{C}$ and a cooling rate of $20 \mathrm{~K} / \mathrm{min}$ in all cases. The $\beta S \mathrm{n}$ nucleation undercooling was defined as the difference between the onset on heating and the onset on cooling temperatures.

Analytical SEM was conducted on a Zeiss AURIGA FEG-SEM equipped with an Oxford Instruments INCA x-sight energy dispersive X-ray (EDX) detector and a Bruker electron backscatter diffraction (EBSD) detector. 


\subsection{Nucleation undercooling in freestanding solder balls}

The nucleation undercooling of $\beta \mathrm{Sn}$ in freestanding $\mathrm{Sn}-0.7 \mathrm{Cu}-0.05 \mathrm{Ni}$ solder balls is overviewed and compared with Sn-Ag-Cu solders in Figure 1. There is a significant size effect on the nucleation undercooling as shown in Figure 1A. It can be seen that reducing the size/mass of a solder ball both increases the mean nucleation undercooling and significantly increases the standard deviation. Note that, for a $0.5 \mathrm{~kg}$ sample cooled at $\sim 1 \mathrm{~K} / \mathrm{s}$, the same alloy gave a nucleation undercooling of $6.8 \pm 0.8 \mathrm{~K}$. The origin of the volume effect most likely comes from two sources. First, by dividing into smaller particles, the probability of a droplet containing a potent nucleant decreases and, in most droplets, nucleation occurs on less potent nucleation sites [34]. Second, the heterogeneous nucleation rate scales with the number of nucleant particles in the liquid [35]. It has also been shown that the nucleation rate of tin in solder joints is relatively low [36].

Figure 1B shows the nucleation undercooling for 80 cycles of two $300 \mu \mathrm{m}$ Sn-0.7Cu-0.05Ni balls. There is a wide scatter in undercooling measurements with little trend in undercooling versus cycle number and a mean undercooling of $\sim 50 \mathrm{~K}$ in each ball. Figure $1 \mathrm{C}$ compares the nucleation undercooling of $\mathrm{Sn}-0.7 \mathrm{Cu}-0.05 \mathrm{Ni}$ with past work on $\mathrm{Sn}-\mathrm{Ag}$-Cu solders $[7,9,37]$ where undercooling is plotted versus the inverse solder ball diameter. $\mathrm{Sn}-0.7 \mathrm{Cu}-0.05 \mathrm{Ni}$ and $\mathrm{Sn}-\mathrm{Ag}-\mathrm{Cu}$ solders have similar size-undercooling trend but there is substantial difference in the magnitude of the undercooling for different authors. This has been shown to be at least partly due to differences in alloy purity [9]. Figure $1 \mathrm{C}$ also indicates the typical ranges of solder sizes in different electronic packaging technologies. It can be seen that, for small ball grid arrays (BGAs) and flip chip joints, substantial undercoolings of $\sim 30-80 \mathrm{~K}$ are predicted by this plot and the trend suggests that undercooling would become even larger as joint miniaturisation continues. However, as will be seen later in this paper, the undercooling for $\beta S n$ is strongly affected by the presence of a substrate (i.e. soldering to a surface finish or metallization). 


\subsection{Tin grain structure in freestanding solder balls}

Two microstructures typical of $550 \mu \mathrm{m}$ freestanding $\mathrm{Sn}-3 \mathrm{Ag}-0.5 \mathrm{Cu}$ balls with nucleation undercooling in the range $20-30 \mathrm{~K}$ are overviewed in Figure 2 . Both balls contain $\beta \mathrm{Sn}$ dendrites and eutectic. Throughout this paper, our use of the term 'eutectic' does not imply anything about growth mechanisms. Further work is required to understand eutectic growth mechanisms in solder joints solidifying in undercooled melts including whether eutectic growth can be divorced for some compositions.

In the cross-polarised optical micrograph of Figure $2 \mathrm{~A}$, the $\beta S \mathrm{Sn}$ dendrite morphology is discernible and, from the EBSD map in Figure 2B, it can be seen that the dendrite growth directions are close to $[110]$ and $[1 \overline{1} 0]$. This is expected based on past work which reports tetragonal tin to have $<110>[38]$ or $\sim 12^{\circ}$ from $<110>[39,40]$ as the preferred growth directions. The EBSD inverse pole figure (IPF) maps in Figures $2 \mathrm{~B}, \mathrm{C}$ show that there are multiple $\beta \mathrm{Sn}$ orientations in each $\mathrm{Sn}-3 \mathrm{Ag}-0.5 \mathrm{Cu}$ ball, but the misorientation (MO) histograms and pole figures (Figures $2 \mathrm{E}, \mathrm{F}$ ) show that all grains are twinned, suggesting that there was only a single nucleation event in each ball. In particular, all grains share a common $[010]$ direction and are rotated $\sim 60^{\circ}$ relative to their neighbours, which is consistent with either $57.2^{\circ}\{101\}$ or $62.8^{\circ}\{301\}$ twinning. This result is well-known (e.g. $\left.[9,11,13,18]\right)$ and a discussion on the origin of solidification twinning in solder balls is given in refs $[9,11]$. We additionally highlight the following three reproducible phenomena of SAC solidification that can be seen or inferred in Figure 2A-F. First, the eutectic tin has the same orientation as the primary tin dendrite. Note that, while this is common in solidification, it does not need to be the case. For example, in modified Al-Si alloys, eutectic grains can nucleate independently and eutectic Al often has a different orientation to the primary Al dendrites [41]. Second, Sn-Sn grain boundaries are often created by eutectic growth (e.g. see Figure 2D). Third, solidification twinning creates incoherent Sn-Sn interfaces, where the lattices are related by a twin OR but the grain boundary orientation is arbitrary because they form by the impingement of complex-shaped growth fronts a significant distance from the initial twinning event(s). For example, in Figure 2(D), it can be seen that dendrite arms belonging to different 
grains are interlaced. In this case the grain boundary orientation is different at every point along the curved dendrite arm. A similar arbitrary interface orientation also occurs when dendritic grains meet without interlacing. In the literature, it has been shown that a range of $\beta$ Sn grain structures can form in $\mathrm{Sn}-3 \mathrm{Ag}-0.5 \mathrm{Cu}$ depending on the nucleation undercooling, but all grains are usually twinned suggesting a single nucleation event in most cases [9].

A typical Sn-0.7Cu-0.05Ni freestanding solder ball is shown in Figure 3. The $\beta \mathrm{Sn}$ grain structure is significantly different to SAC freestanding balls (Figure 2): in Sn-0.7Cu-0.05Ni (Figure 3) there are more $\beta \mathrm{Sn}$ grain orientations (more colours in the inverse pole figure map of Figure $3 \mathrm{~A}$ ) and a much wider range of grain boundary misorientations (Figure 3B) than in SAC balls. It is not obvious from the MO histogram (Figure 3B) or the pole figures (not shown) whether there is any solidification twinning or other special high-angle boundaries. Examination of the microstructure in Figure 3A shows long $\beta$ Sn plates often spanning the width of the cross-section. Four such plates are isolated in Figure 3C. We found these plates to form in every sample that solidified after a nucleation undercooling of $\sim 40 \mathrm{~K}$ or higher, indicating that these are rapid growth structures that formed at the beginning of solidification. Figure $3 C$ is an EBSD IPF map of four of these $\beta$ Sn plates (note that their dendritic arms are not included in the isolated map) with the unit cell orientations superimposed, and Figure 3D shows pole figures from these four plates. It can be seen that all four plates share a common [010] direction, making it likely that they have grown from one nucleation event, and are rotated $\sim 20-36^{\circ}$ relative to their neighbours. Lehman et al. [11] reported similar phenomena in $\mathrm{Sn}-0.1 \mathrm{Cu}$, but their plates had $a \sim 60^{\circ}$ twin relationship about a [010] axis. The results in Figure $3 C, D$ and those of Lehman et al. have strong similarities when we note that plates i and iii are rotated $\sim 57^{\circ}$ about [010] and plates ii and iv are rotated $\sim 60^{\circ}$ about [010], consistent with solidification twinning. Other groups of plates in Figure $3 \mathrm{~A}$ have a similar relationship to each other but not to the four plates in Figure $3 C, D$, indicating that there were multiple nucleation events in this ball. 


\subsection{Tin grain structure in solder balls on common substrates}

Various studies have found that the nucleation undercooling for tin can be reduced somewhat by the presence of a $\mathrm{Cu}$ or $\mathrm{Ni}$-based substrate and that $\mathrm{Ni}$ substrates reduce undercooling more than $\mathrm{Cu}[8,10,37,42,43]$. We find three key differences to the solidification of solder balls when soldered to $\mathrm{Cu}$ or Ni substrates: (i) the nucleation undercooling is usually significantly reduced, particularly in higher purity samples where the freestanding ball undercooling is high, (ii) $\beta$ Sn often grows from the substrate, and (iii) substrate dissolution can significantly change the phases that form during solidification, particularly when the substrate is not a component of the solder. We illustrate these points using $\mathrm{Sn}-3 \mathrm{Ag}-0.5 \mathrm{Cu} / \mathrm{Cu}, \mathrm{Sn}-0.7 \mathrm{Cu}-0.05 \mathrm{Ni} / \mathrm{Cu}$ and $\mathrm{Sn}-3.5 \mathrm{Ag} / \mathrm{Ni}$ joints as examples.

Figure 4 shows the typical microstructure of a Sn-3Ag-0.5Cu ball soldered to $\mathrm{Cu}$. Figure $4 \mathrm{~A}$ is an EBSD IPF map with unit cell orientations superimposed. In this particular case, there are two tin orientations with a low angle boundary. Examination of the pole figure in Figure $4 \mathrm{~B}$ shows that the two grains share a common [110] direction and are rotated by $\sim 7-10^{\circ}$. This may well be a $\sum 30$ coincidence site lattice (CSL) boundary which has $7.3^{\circ}$ misorientation about [110] (e.g. [18]). It is likely that there was a single nucleation event and that the CSL boundary developed as a mechanism for growth to fan-out from the nucleation site. Note that, while Figure 4 shows a near-single $\beta S n$ orientation, it is also common for 2-6 twinned grains and 'beach ball' morphologies to be present in $\mathrm{SAC} / \mathrm{Cu}$ joints similar to freestanding balls [11]. Figure 4A also shows that the [110] direction is consistent with $\beta$ Sn dendrite growth from the substrate. To explore this further, SEM images of the same sample after shallow etching are shown in Figures 4 C,D. It can be seen that the $\beta$ Sn dendrite growth direction is close to $<110>$ and the dendrite geometry is consistent with growth from (or from near) the $\mathrm{Cu}_{6} \mathrm{Sn}_{5}$ reaction layer. Additionally, the dendrite spacing is significantly smaller close to the $\mathrm{Cu}_{6} \mathrm{Sn}_{5}$ reaction layer (Figure 4D) than further from the layer (e.g. Figure 4C), consistent with the earliest stages of growth occurring near to the $\mathrm{Cu}_{6} \mathrm{Sn}_{5}$ layer at high undercooling before latent heat release reduced the undercooling. 
Figure 5 shows the typical microstructure of a $\mathrm{Sn}-0.7 \mathrm{Cu}-0.05 \mathrm{Ni}$ ball soldered to $\mathrm{Cu}$. Figure $5 \mathrm{~A}$ is an EBSD IPF map with unit cell orientations superimposed. There are a variety of $\beta$ Sn orientations with almost no twin boundaries in this cross-section, suggesting that there were multiple nucleation events. Each $\mathrm{Sn}$ grain orientation is consistent with [110] growth from the $\mathrm{Cu}_{6} \mathrm{Sn}_{5}$ reaction layer, as indicated by the unit cells superimposed on the EBSD map. Additionally, there are more $\beta$ Sn grains near the substrate and a decreasing number of grains further away from the substrate in Figure $5 \mathrm{~A}$, which is indicative of grain selection by competitive growth away from the reaction layer, reminiscent of the growth of a columnar zone out of a chill zone near the wall of a casting [34]. Similar microstructures were reported in $\mathrm{Sn}-\mathrm{Cu} / \mathrm{Cu}$ joints by Seo et al. [44]. Note that there are no "long plates" in Figure 5A such as those in freestanding Sn-0.7Cu-0.05Ni (e.g. Fig. 4A]. This is most likely due to the significantly decreased nucleation undercooling on Cu substrates ( $24 \mathrm{~K}$ in Fig. 5 vs. $47 \mathrm{~K}$ in Fig. 3) since we observed that long plates only formed at undercoolings $\geq 40 \mathrm{~K}$ in freestanding balls.

An interesting feature of $\mathrm{Sn}-07 \mathrm{Cu}-0.05 \mathrm{Ni} / \mathrm{Cu}$ joints is that no $\beta \mathrm{Sn}$ dendrites are discernable in the microstructure (for the level of undercooling shown), e.g. neither in the EBSD quality maps nor after shallow etching. Instead, small $\left(0.5-0.8 \mu \mathrm{m}\right.$ wide) $(\mathrm{Cu}, \mathrm{Ni})_{6} \mathrm{Sn}_{5}$ rods are present throughout each grain as shown in Fig. 5D. Thus, it is concluded that the grains in Fig. $5 \mathrm{~A}$ are $\beta \mathrm{Sn}-(\mathrm{Cu}, \mathrm{Ni})_{6} \mathrm{Sn}_{5}$ eutectic grains. This is not surprising since $\mathrm{Sn}-0.7 \mathrm{Cu}-0.05 \mathrm{Ni}$ is slightly hypereutectic $[3,31]$ and $\mathrm{Cu}$-dissolution will have increased the Cu composition further. However, the same argument is true for $\mathrm{Sn}-3 \mathrm{Ag}$ $0.5 \mathrm{Cu} / \mathrm{Cu}$ : substrate dissolution at $240^{\circ} \mathrm{C}$ will have brought the liquid to a hypereutectic composition (certainly at the $\mathrm{Cu}_{6} \mathrm{Sn}_{5}$ layer-L interface where we expect local interfacial equilibrium and most likely throughout the liquid of the small joint due to liquid diffusion), and yet, $\mathrm{Sn}-3 \mathrm{Ag}-0.5 \mathrm{Cu} / \mathrm{Cu}$ solidified with a high fraction ( $50 \%$ ) of $\beta$ Sn dendrites (Figure 4C,D) even near the substrate. Similarly, Anderson [45] has shown that slightly hypereutectic Sn-Ag-Cu alloys usually solidify to contain some $\beta S n$ dendrites. This shows the strong role played by growth kinetics on growth competition in solder joints containing faceted phases. After nucleation in an undercooled melt, the type of microstructure that 
grows (primary dendrites ahead of a eutectic front, or a fully-eutectic front etc.) depends on which can grow at highest velocity for the level of undercooling at the growth front $[34,46]$. From Figures 4 and 5, it can be inferred that $\beta S n$ dendrite tips grow fastest in $\mathrm{Sn}-3 \mathrm{Ag}-0.5 \mathrm{Cu} / \mathrm{Cu}$ joints and a eutectic front fastest in $\mathrm{Sn}-0.7 \mathrm{Cu}-0.05 \mathrm{Ni} / \mathrm{Cu}$ for nucleation undercoolings of $15-25 \mathrm{~K}$. This highlights the fact that the presence of $\mathrm{Ag}_{3} \mathrm{Sn}$ in the eutectic growth front leads to a highly skewed coupled zone (also known as eutectic range) as shown by Esaka et al. [1].

Figure 6 shows the typical microstructure of a $\mathrm{Sn}-3.5 \mathrm{Ag}$ ball soldered to $\mathrm{Ni}$ where the nucleation undercooling was $8 \mathrm{~K}$. Note that this lower undercooling (relative to the freestanding solder balls in Figure 1 and to soldering to $\mathrm{Cu}$ substrates) is typical of soldering to Ni substrates [37, 42]. In Figure $6 \mathrm{~A}, \mathrm{~B}$, the $\beta S n$ microstructure is essentially single-grain with misorientations up to $\sim 20^{\circ}$ and the orientation is consistent with [110] growth from the substrate, similar to $\mathrm{Sn}-3 \mathrm{Ag}-0.5 \mathrm{Cu} / \mathrm{Cu}$ and $\mathrm{Sn}$ $0.7 \mathrm{Cu}-0.05 \mathrm{Ni} / \mathrm{Cu}$ joints. Shallow etching (Figure $6 \mathrm{C}, \mathrm{D}$ ) shows that solidification occurred by primary $\beta S n$ dendrite growth followed by eutectic reactions. With higher magnification analytical SEM, we have found a surprising result: the eutectic is $\mathrm{Sn}-\mathrm{Ag}_{3} \mathrm{Sn}-\mathrm{NiSn} \mathrm{n}_{4}$ and not the $\mathrm{Sn}-\mathrm{Ag}_{3} \mathrm{Sn}-\mathrm{Ni}_{3} \mathrm{Sn}_{4}$ expected of equilibrium solidification [47]. That is to say, metastable $\mathrm{NiSn}_{4}$ forms during the solidification of $\mathrm{Sn}$ 3.5 Ag/Ni joints. Note that, in Figure 6, the substrate is $99.9 \%$ pure $\mathrm{Ni}$ to make the point that metastable $\mathrm{NiSn}_{4}$ forms when only $\mathrm{Sn}, \mathrm{Ag}$ and $\mathrm{Ni}$ are present. Further details of metastable $\mathrm{NiSn}_{4}$ in $\mathrm{Sn}-3.5 \mathrm{Ag} / \mathrm{Ni}$ and more complex $\mathrm{Ni}(\mathrm{P}) / \mathrm{Au} / \mathrm{Sn} 3.5 \mathrm{Ag}$ joints including phase identification by combining EBSD and EDX are given in our past work $[47,48]$. We have also shown that a binary metastable Sn$\mathrm{NiSn}_{4}$ eutectic grows over a wide range of solidification conditions in the $\mathrm{Sn}-\mathrm{Ni}$ system which is discussed in refs $[48,49]$.

From Figures 4-6, it is clear that the presence of either a $\mathrm{Cu}$ or $\mathrm{Ni}$ substrate reduces the nucleation undercooling for $\beta$ Sn (compared to the freestanding balls in Figures 2-3) and triggered nucleation on or near the intermetallic layer at the solder-substrate interface. A natural question then 
arises: what is the best substrate for controlling the nucleation and growth of tin in soldering? To explore this, we performed a basic study on tin nucleation in pure tin / pure metal joints where $99.9 \%$ $\mathrm{Fe}, \mathrm{Co}, \mathrm{Ir}, \mathrm{Ni}, \mathrm{Pd}, \mathrm{Pt}, \mathrm{Au}, \mathrm{Ag}$ and $\mathrm{Cu}$ sheet were used as substrates.

\subsection{Exploring other substrates}

Figure 7 shows the mean nucleation undercooling for $\beta$ Sn during solder reactions between 99.9\% $\mathrm{Sn}$ and $99.9 \% \mathrm{Fe}, \mathrm{Co}, \mathrm{Ir}, \mathrm{Ni}, \mathrm{Pd}, \mathrm{Pt}, \mathrm{Au}, \mathrm{Ag}$ and $\mathrm{Cu}$ substrates. Note that relatively large solder foils (relative to Figure 1 ) of $3.5 \times 3.5 \times 0.1 \mathrm{~mm}(9 \mathrm{mg})$ were used to reduce the scatter in undercooling measurements which resulted in a relatively low nucleation undercooling for the sample with no substrate. Figure 7 shows that all of the substrates tested reduced the nucleation undercooling for $\beta S n$ to some extent and that some substrates reduced the undercooling substantially. A key result in Figure 7 is that $\mathrm{Co}, \mathrm{Pd}$ and Pt substrates give the lowest nucleation undercooling for $\beta \mathrm{Sn}$ of $\sim 3 \mathrm{~K}$ in each case, which is much lower than commonly used substrates ( $\mathrm{Cu}, \mathrm{Ni}, \mathrm{Ag})$.

Of the three most effective substrates, we have examined nucleation of $\beta \mathrm{Sn}$ in $\mathrm{Sn} / \mathrm{Pt}$ and Sn/Pd joints so far. Here the IMC reaction layers are $\mathrm{PtSn}_{4}$ and $\mathrm{PdSn}_{4}$ which are isomorphous phases and have similar lattice parameters [50]. EBSD mapping of the reaction layer and $\beta S n$ gives insight into the reduced nucleation undercooling. Figure 8 shows an EBSD IPF map from a Sn/Pt joint. There is a single $\beta S n$ grain above a polycrystalline $\mathrm{PtSn}_{4}$ reaction layer. The $\mathrm{PtSn}_{4}$ pole figures show a [110] preferred growth direction in the $\mathrm{PtSn}_{4}$ reaction layer with grains rotated to different degrees around [110] (i.e. PtSn 4 has a [110] fibre texture). It is not possible to know where the $\beta$ Sn nucleated from Figure 8 , but the $\beta \mathrm{Sn}$ and $\mathrm{PtSn}_{4}$ pole figures contain some $\mathrm{PtSn}_{4}$ grains that have an orientation relationship with $\beta S n$ close to that observed in $\beta S_{n}-\mathrm{PtSn}_{4}$ lamellar eutectic growth [50]: [001 $]_{\mathrm{sn}}$ II $[100]_{\mathrm{PtSn} 4}$ and $[100]_{\mathrm{Sn}}$ II [001 $]_{\mathrm{PtSn} 4}$ with $(001)_{\mathrm{PtSn} 4}$ as the interfacial plane. This OR has been shown to be a relatively good lattice match [50] and is most probably the origin of the low nucleation undercooling for $\beta$ Sn during soldering to Pt (Fig. 7). We note that the nucleation site is statistically unlikely to be in 
this cross-section but that an interface with the OR above is highly likely to exist for a $\mathrm{PtSn}_{4}$ grain somewhere on the $\mathrm{PtSn}_{4}-\beta S n$ interface. In support of this, Figure $8(\mathrm{~A})$ confirms that $(001)_{\mathrm{PtSn}_{4}}$ facets protrude from the $\mathrm{PtSn}_{4}$ layer and were available as nucleation sites (see ref [50] for detail). Furthermore, it is shown in ref [50] that an almost identical $\beta$ Sn grain orientation forms over an isomorphous $\mathrm{PdSn}_{4}$ reaction layer when $\mathrm{Sn}$ is soldered to pure $\mathrm{Pd}$. These measurements and observations all support the conclusion that $\beta \mathrm{Sn}$ nucleates on the $\mathrm{PtSn}_{4} / \mathrm{PdSn}_{4}$ reaction layer and that $\mathrm{PtSn}_{4}$ and $\mathrm{PdSn}_{4}$ are potent nucleation sites for tin. It is interesting to note that although the nucleation undercooling is substantially reduced, the tin grain size is not altered. However, nucleation on the IMC layer may offer a potential way to control the orientation of the tin grains since the $\mathrm{PtSn} 4$ / $\mathrm{PdSn} n_{4}$ layer has a reproducible growth texture and $\beta \mathrm{Sn}$ nucleates on $\mathrm{PtSn}_{4} / \mathrm{PdSn}_{4}$ with a reproducible OR.

Note that the metastable $\mathrm{NiSn}_{4}$ that grows by eutectic solidification in $\mathrm{Sn}-3.5 \mathrm{Ag} / \mathrm{Ni}$ joints (Figure 6 and ref [47]) is isomorphous to $\mathrm{PdSn}_{4}$ and $\mathrm{PtSn}_{4}$ (all are orthorhombic with the oC20-PtSn 4 prototype) with similar lattice parameters. We have shown that, if the intermetallic layer in $\mathrm{Sn}-\mathrm{Ni}$ joints is engineered to be $\mathrm{NiSn}_{4}$, then the nucleation undercooling for tin is low and very similar to when a $\mathrm{PdSn}_{4}$ and $\mathrm{PtSn}_{4}$ layer is present (see ref. [50] for detail). That is to say, the nucleation undercooling for $\mathrm{Sn}$ is significantly lower when the intermetallic layer on the liquid side is metastable $\mathrm{NiSn}_{4}$ rather than $\mathrm{Ni}_{3} \mathrm{Sn}_{4}$ in $\mathrm{Sn} / \mathrm{Ni}$ joints [50], further supporting the idea of epitaxial nucleation of $\beta \mathrm{Sn}$ on isomorphous $\mathrm{XSn}_{4}$ phases $(\mathrm{X}=\mathrm{Pd}, \mathrm{Pt}, \mathrm{Ni})$.

Figure 1 showed that there are significant size-effects for the nucleation of freestanding solder balls. Figure 9 explores size effects during soldering of tin to $\mathrm{Cu}$ and $\mathrm{Pd}$ substrates. In Figure 9A, it can be seen that the nucleation undercooling is higher in $\mathrm{Sn} / \mathrm{Cu}$ joints than $\mathrm{Sn} / \mathrm{Pd}$ joints at all solder volumes studied and that there is a stronger size effect in $\mathrm{Sn} / \mathrm{Cu}$. Figure 9B shows the DSC response for 7 reflow cycles of a $0.2 \mathrm{mg} 99.9 \%$ Sn ball soldered to Pd. There is a decreasing peak integral with each solder melting cycle due to the consumption of tin during $\mathrm{PdSn}_{4}$ layer growth. After 7 cycles there 
is no $\mathrm{Sn}$ left as can be seen from the lack of a peak on heating or cooling in the $7^{\text {th }}$ cycle. Importantly, the nucleation undercooling for tin is $4 \pm 0.8 \mathrm{~K}$ for all cycles and there is no discernable trend in undercooling versus cycle number in Sn/Pd. The peak integral on the $6^{\text {th }}$ heating is $\sim 1 / 10^{\text {th }}$ of the first heating cycle, suggesting that the mass of $\mathrm{Sn}$ in the $6^{\text {th }}$ cycle is $\sim 0.02 \mathrm{mg}$ which corresponds to a $<200 \mu \mathrm{m}$ diameter ball. It can be inferred from this that the undercooling stays almost the same regardless of the volume of Sn; i.e. there is no significant solder volume effect in Sn/Pd joints in contrast to freestanding solder balls in Figure 1. This can be understood based on the presence of a potent nucleant (the $\mathrm{PdSn}_{4}$ layer) irrespective of the solder volume.

Factors that may lead to preferred nucleation on or near the IMC reaction layer include: (1) epitaxial nucleation on the IMC reaction layer or other reaction product (if there is a good lattice match between an IMC facet plane and $\beta$-Sn such as with $\mathrm{PtSn}_{4}$ and $\left.\mathrm{PdSn}_{4}\right)$; (2) geometric nucleation in the grooves of the intermetallic layer (similar to [35, 51]); (3) constitutional-supercooling-driven nucleation in the liquid near the IMC layer where the liquid is most Sn-rich; (4) changes in interfacial energies or liquid structure due to dissolved atoms in the liquid; (5) the thermal gradient: If the heat flux direction is into the substrate, liquid near the substrate is the coldest in the joint. Based on the markedly different undercoolings in Figure 7, it is expected that the relative importance of 1-4 is different for different substrates, although this has not been explored in detail.

\section{$4 \quad$ Conclusions}

The formation of the $\beta \mathrm{Sn}$ grain structure in $\mathrm{Pb}$-free solder joints has been overviewed using Sn-3Ag-0.5Cu, Sn-0.7Cu-0.05Ni and Sn-3.5Ag as examples. In addition to solidification twinning which has been studied in detail previously, we highlight a number of other phenomena that are important in determining the $\beta S n$ grain structure and grain orientations. It has been shown that at least $~ 50 \%$ 
of $\beta \mathrm{Sn}$ forms during eutectic reactions and that there is competitive growth between primary dendrite tips and nonfaceted-faceted eutectic growth fronts in joints. Furthermore, in the case of $\mathrm{Sn}-3.5 \mathrm{Ag} / \mathrm{Ni}$ joints, it is found that a metastable eutectic, $\beta S n-\mathrm{Ag}_{3} \mathrm{Sn}-\mathrm{NiSn} n_{4}$, grows instead of the $\beta \mathrm{Sn}-\mathrm{Ag}_{3} \mathrm{Sn}_{\mathrm{N}}-\mathrm{Ni}_{3} \mathrm{Sn}_{4}$ expected of equilibrium solidification [47].

It has been shown that $\mathrm{Sn}-0.7 \mathrm{Cu}-0.05 \mathrm{Ni}$ solidifies to produce a markedly different grain structure to $\mathrm{Sn}-3 \mathrm{Ag}-0.5 \mathrm{Cu}$ both during the solidification of freestanding solder balls and during soldering to $\mathrm{Cu}$ substrates. A significant difference is that the tin in $\mathrm{Sn}-3 \mathrm{Ag}-0.5 \mathrm{Cu} / \mathrm{Cu}$ joints mostly forms by primary dendrite growth whereas, in $\mathrm{Sn}-0.7 \mathrm{Cu}-0.05 \mathrm{Ni} / \mathrm{Cu}$ joints, tin grows as eutectic grains at the levels of undercooling studied.

Additionally, it is shown that the substrate (metallization) has a strong influence on the nucleation and growth of tin. We identify $\mathrm{Co}, \mathrm{Pd}$ and Pt substrates as having potential to control solidification and microstructure formation. In the case of Pd and Pt substrates, $\beta S n$ is shown to nucleate on the $\mathrm{PtSn}_{4}$ or $\mathrm{PdSn}_{4} \mathrm{IMC}$ reaction layer at relatively low undercooling of $\sim 4 \mathrm{~K}$, even for small solder joints down to $<200 \mu \mathrm{m}$. By optimising the substrate, it is possible to control undercooling and the $\beta S n$ grain orientation(s) in solder joints.

\section{$4 \quad$ Acknowledgements}

We thank Nihon Superior Co., Ltd. and the UK EPSRC (grant \# EP/M002241/1) for funding and K. Sweatman for valuable discussions. 


\section{References}

[1] H. Esaka, K. Shinozuka, M. Tamura,: Mater. Trans., 46, 916-921 (2005).

[2] R.J. Schaefer, D.J. Lewis, Metall. Mater. Trans. A, 36, 2775-2783 (2005).

[3] C.M. Gourlay, K. Nogita, A.K. Dahle, Y. Yamamoto, K. Uesugi, T. Nagira, M. Yoshiya, H. Yasuda, Acta Mater., 59, 4043-4054 (2011).

[4] L.M. Hogan, R.W. Kraft, F.D. Lemkey, Adv. Mater. Res., 5, 83 (1971).

[5] P. Magnin, W. Kurz, Acta Metall., 35, 1119-1128 (1987).

[6] J.H. Perepezko, Mater. Sci. Eng., 65, 125-135 (1984).

[7] R. Kinyanjui, L.P. Lehman, L. Zavalij, E. Cotts, J. Mater. Res., 20, 2914-2918 (2005).

[8] S.K. Kang, M.G. Cho, P. Lauro, D.Y. Shih, 57th IEEE Electronic Components \& Technology

Conference (ECTC), 1597-1603 (2007).

[9] B. Arfaei, N. Kim, E.J. Cotts, J. Electron. Mater., 41, 362-374 (2012).

[10] J.W. Elmer, E.D. Specht, M. Kumar, J. Electron. Mater., 39, 273-282 (2010).

[11] L.P. Lehman, Y. Xing, T.R. Bieler, E.J. Cotts, Acta Mater., 58, 3546-3556 (2010).

[12] L.P. Lehman, S.N. Athavale, T.Z. Fullem, A.C. Giamis, R.K. Kinyanjui, M. Lowenstein, K. Mather, R. Patel, D. Rae, J. Wang, Y. Xing, L. Zavalij, P. Borgesen, E.J. Cotts, J. Electron. Mater., 33, 1429-1439 (2004).

[13] S. Yang, Y. Tian, C. Wang, J. Mater. Sci.: Mater. Electron., 21, 1174-1180 (2010).

[14] G. Parks, B. Arfaei, M. Benedict, E. Cotts, M. Lu, E. Perfecto, 62nd IEEE Electronic Components and Technology Conference (ECTC), 703-709 (2012).

[15] I.E. Anderson, J.W. Walleser, J.L. Harringa, F. Laabs, A. Kracher, J. Electron. Mater., 38, $2770-$ 2779 (2009).

[16] S.K. Kang, D.Y. Shih, N.Y. Donald, W. Henderson, T. Gosselin, A. Sarkhel, C. Goldsmith, K.J. Puttlitz, C. W.K., JOM, 55, 61-65 (2003).

[17] P. Darbandi, T.R. Bieler, F. Pourboghrat, T.K. Lee, J. Electron. Mater., 42, 201-214 (2013).

[18] A.U. Telang, T.R. Bieler, JOM, 57, 44-49 (2005).

[19] E.V. Vernon, S. Weintraub, Proc. Phys. Soc., Sect. B., 66, 887 (1953).

[20] J.A. Rayne, B.S. Chandrasekhar, Phys. Rev., 120, 1658-1663 (1960).

[21] D.C. Yeh, H.B. Huntington, Phys. Rev. Lett., 53, 1469 (1984).

[22] C. Kinney, X. Linares, K.O. Lee, J.W. Morris Jr., J. Electron. Mater., 42, 607-615, (2013).

[23] M. Lu, D.Y. Shih, P. Lauro, C. Goldsmith, D.W. Henderson, Appl. Phys. Lett., 92, 211909 (2008).

[24] C.M. Gourlay, J. Read, K. Nogita, A.K. Dahle, J. Electron. Mater., 37, 51-60 (2008).

[25] D.V. Ragone, C.M. Adams, H.F. Taylor, AFS Trans., 64, 653-657 (1956).

[26] K. Nogita, T. Nishimura, Scr. Mater., 59, 191-194 (2008).

[27] R. Schueller, N. Blattau, J. Arnold, C. Hillman, SMTA Journal, 23, 18-26 (2010).

[28] H. Tsukamoto, T. Nishimura, S. Suenaga, S.D. McDonald, K.W. Sweatman, K. Nogita,

Microelectron. Reliab., 51, 657-667 (2011).

[29] C.Y. Li, G.J. Chiou, J.G. Duh, J. Electron. Mater., 35, 343-352 (2006).

[30] V. Vuorinen, H. Yu, T. Laurila, J.K. Kivilahti, J. Electron. Mater., 37, 792-805 (2008).

[31] C.M. Gourlay, K. Nogita, J. Read, A.K. Dahle, J. Electron. Mater., 39, 56-69 (2010).

[32] M. Laentzsch,1st Electronic Systemintegration Technology Conference, IEEE, 383-386 (2006).

[33] A. Donaldson, R. Aspandiar, K. Doss, APEX conference, April (2008).

[34] J.A. Dantzig, M. Rappaz, Solidification, (EPFL Press, 2009).

[35] D. Turnbull, J. Chem. Phys., 18, 198-203 (1950).

[36] B. Arfaei, M. Benedict, E.J. Cotts, J. Appl. Phys., 114(17), 173506 (2013).

[37] Y.C. Huang, S.W. Chen, K.S. Wu, J. Electron. Mater., 39, 109-114 (2010).

[38] F. Weinberg, B. Chalmers, Can. J. Phys., 30, 488-502 (1952).

[39] G.L. Powell, G.A. Colligan, V.A. Surprenant, A. Urquhart, Metall. Trans. A, 8, 971-973 (1977).

[40] S. O'Hara, J. Cryst. Growth, 1, 73-78, (1967).

[41] A.K. Dahle, K. Nogita, S.D. McDonald, C. Dinnis, L. Lu, Mater. Sci. Eng. A, 413, 243-248 (2005).

[42] M.G. Cho, S.K. Kang, H.M. Lee, J. Mater. Res., 23, 1147-1154 (2008). 
[43] G. Parks, A. Faucett, C. Fox, J. Smith, E. Cotts, JOM, 66, 2311-2319 (2014).

[44] S.K. Seo, S.K. Kang, M.G. Cho, D.Y. Shih, H.M. Lee, J. Electron. Mater., 38, 2461-2469 (2009).

[45] I.E. Anderson, J. Mater. Sci.: Mater. Electron., 55-76 (2007).

[46] W. Kurz, P. Gilgien, Mater. Sci. Eng. A, 178, 171-178 (1994).

[47] S.A. Belyakov, C.M. Gourlay, Mater. Lett., 148, 91-95 (2015).

[48] S.A. Belyakov, C.M. Gourlay, Intermetallics, 25, 48-59 (2012).

[49] S.A. Belyakov, C.M. Gourlay, Intermetallics, 37, 32-41 (2013).

[50] S.A. Belyakov, C.M. Gourlay, Acta Mater., 71, 56-68 (2014).

[51] A.J. Page, R.P. Sear, J. Am. Chem. Soc., 131, 17550-17551 (2009). 
Figures
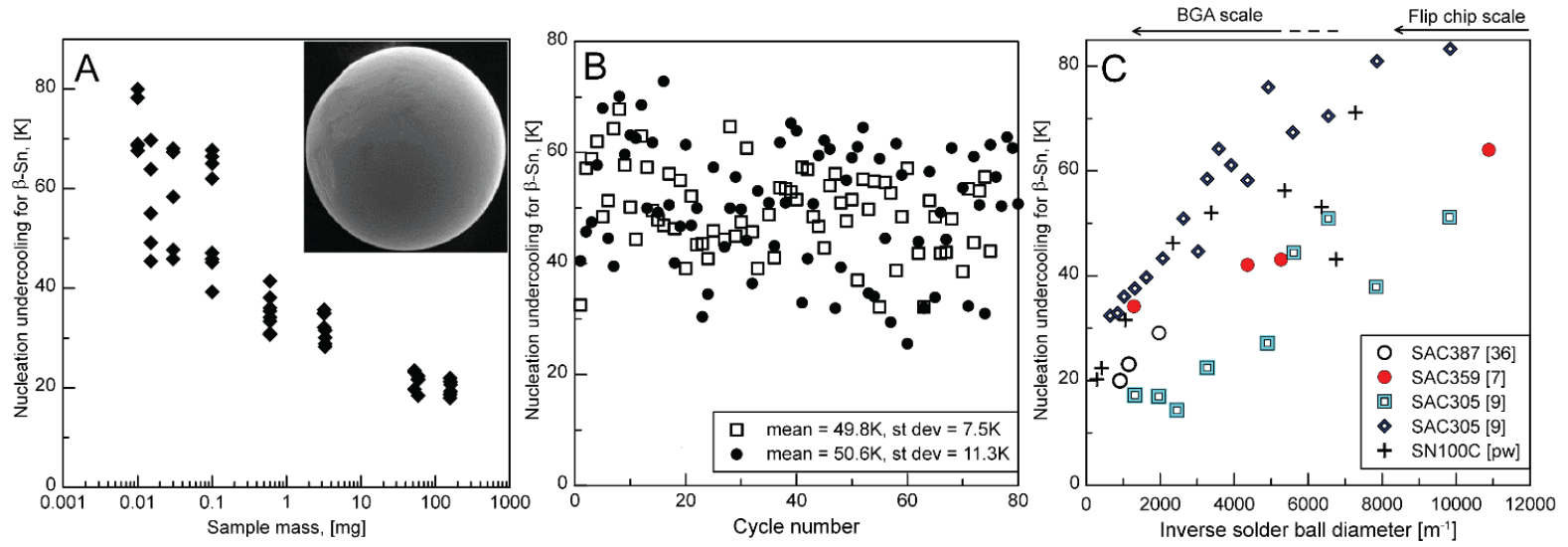

Fig. 1: Nucleation undercooling of $\beta S n$ in freestanding solder balls. (A) influence of sample size in Sn$0.7 \mathrm{Cu}-0.05 \mathrm{Ni}$. (B) 80 cycles of two $300 \mu \mathrm{m}$ Sn-0.7Cu-0.05Ni balls. (C) comparison of Sn-0.7Cu-0.05Ni with literature data on SAC alloys (mean values shown). 

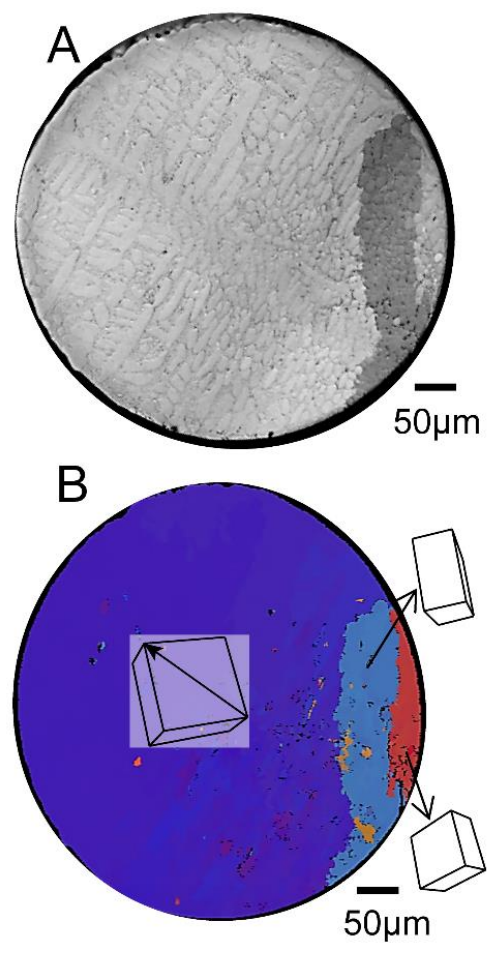
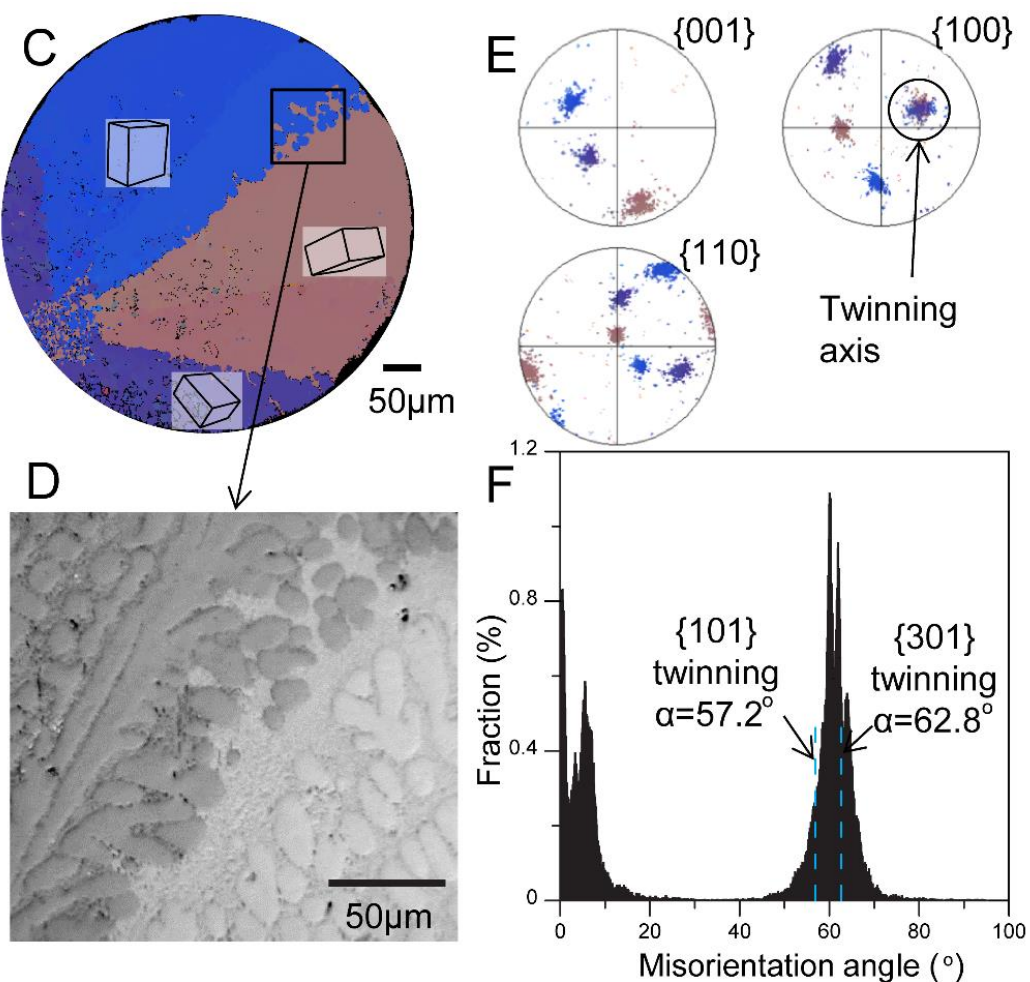

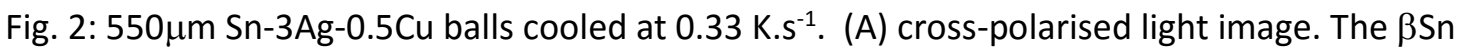
dendrite growth directions are discernible. $\Delta T_{\text {nuc }}=25 \mathrm{~K}$. (B) EBSD $\beta S n$ IPF map of the ball in (A). (C) EBSD $\beta S n$ IPF map of a typical 'beachball' morphology $\left(\Delta T_{\text {nuc }}=22 \mathrm{~K}\right)$. (D) higher magnification image of a $\mathrm{Sn}$-Sn grain boundary from the indicated region in (C).(E) pole figures showing the presence of three $\beta$ Sn grains with a common [010] axis. The colour scales are the same in (E) and (C). (F) misorientation distribution for the sample in (C)-(E). 

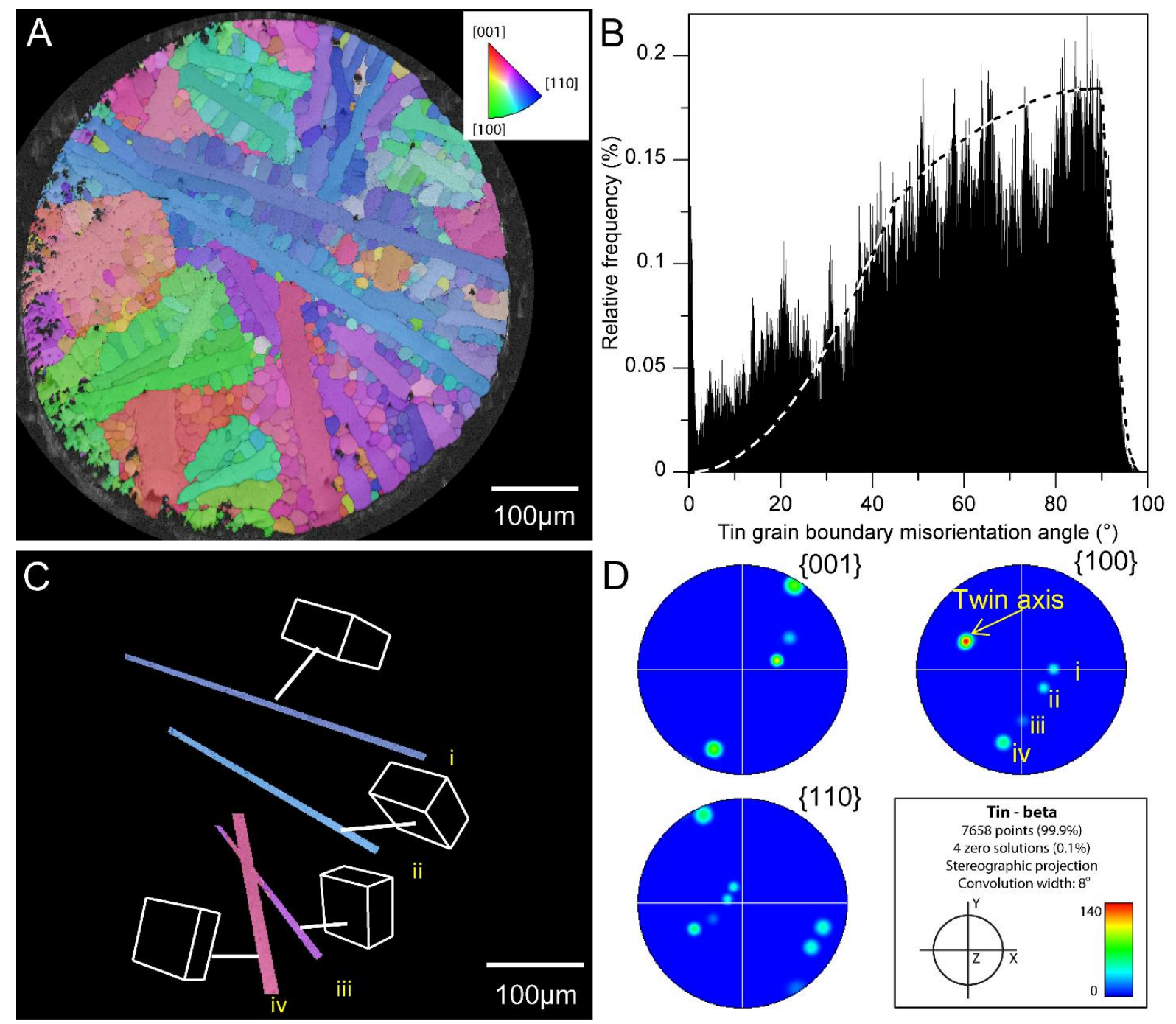

Fig. 3: $550 \mu \mathrm{m}$ Sn-0.7Cu-0.05Ni ball cooled at $0.33 \mathrm{~K}^{-1} \mathrm{~s}^{-1} . \Delta \mathrm{T}_{\text {nuc }}=47 \mathrm{~K}$. (A) EBSD IPF map. (B) Grain boundary misorientation histogram from the map in (A). The dashed line is the expected distribution for randomly oriented Sn grains (MacKenzie plot). (C) Isolation of four plates from the map in (A). Unit cells orientations are shown for each plate. (D) Pole Figures of the four isolated plates in (C) showing the plates share a common[010] axis. 

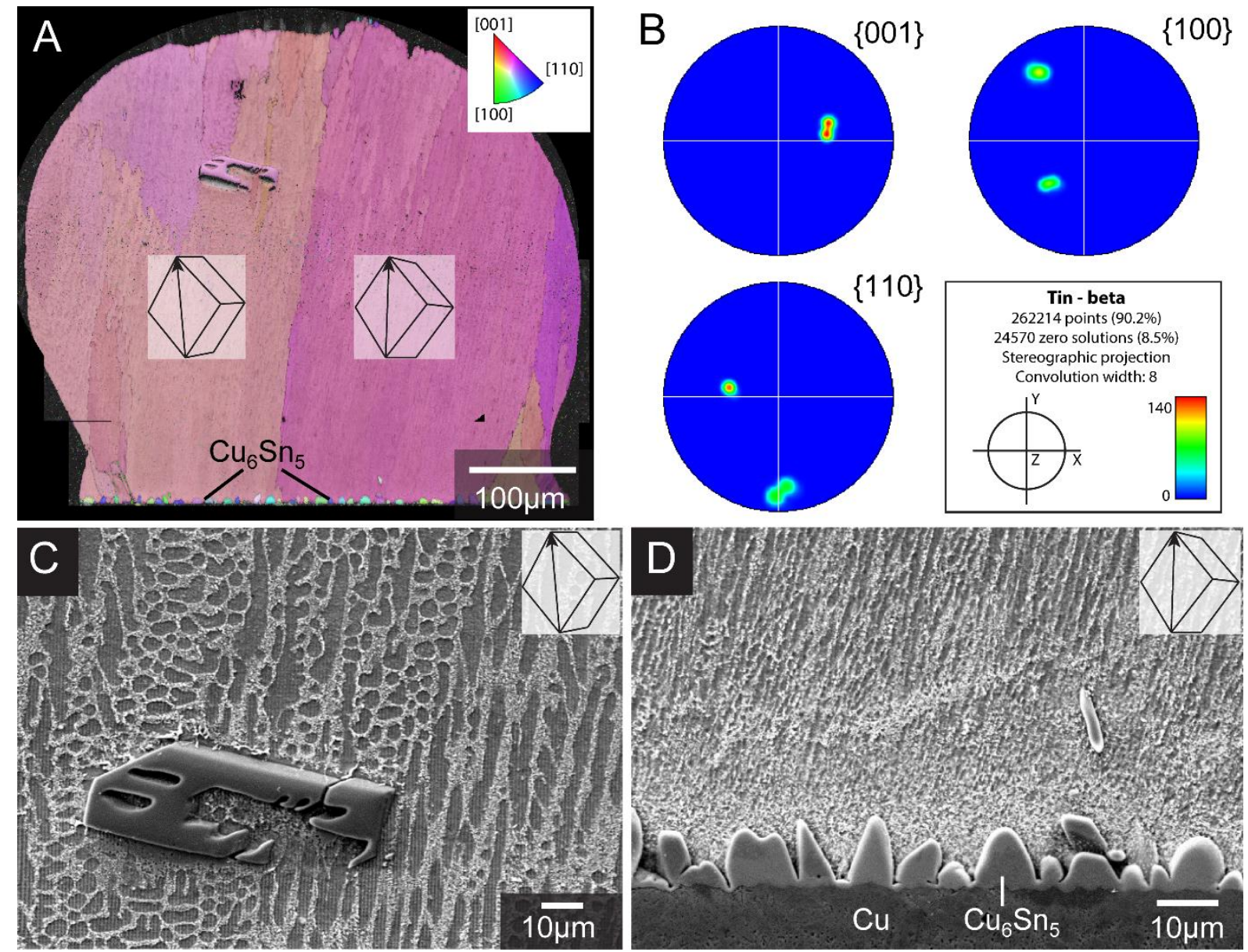

Fig. 4: $550 \mu \mathrm{m}$ Sn-3Ag-0.5Cu/Cu joint cooled at $0.33 \mathrm{~K} \cdot \mathrm{s}^{-1} . \Delta \mathrm{T}_{\text {nuc }}=17 \mathrm{~K}$. (A) EBSD IPF map with unit cell orientations superimposed. (B) Pole figures from the map in (A). (C) image after shallow etching showing $\beta S n$ dendrites near the primary $\mathrm{Cu}_{6} \mathrm{Sn}_{5}$ grain in the upper-middle of $(A)$. (D) image of $\beta S n$ dendrites near the $\mathrm{Cu}_{6} \mathrm{Sn}_{5}$ reaction layer at the bottom of $(\mathrm{A})$. 

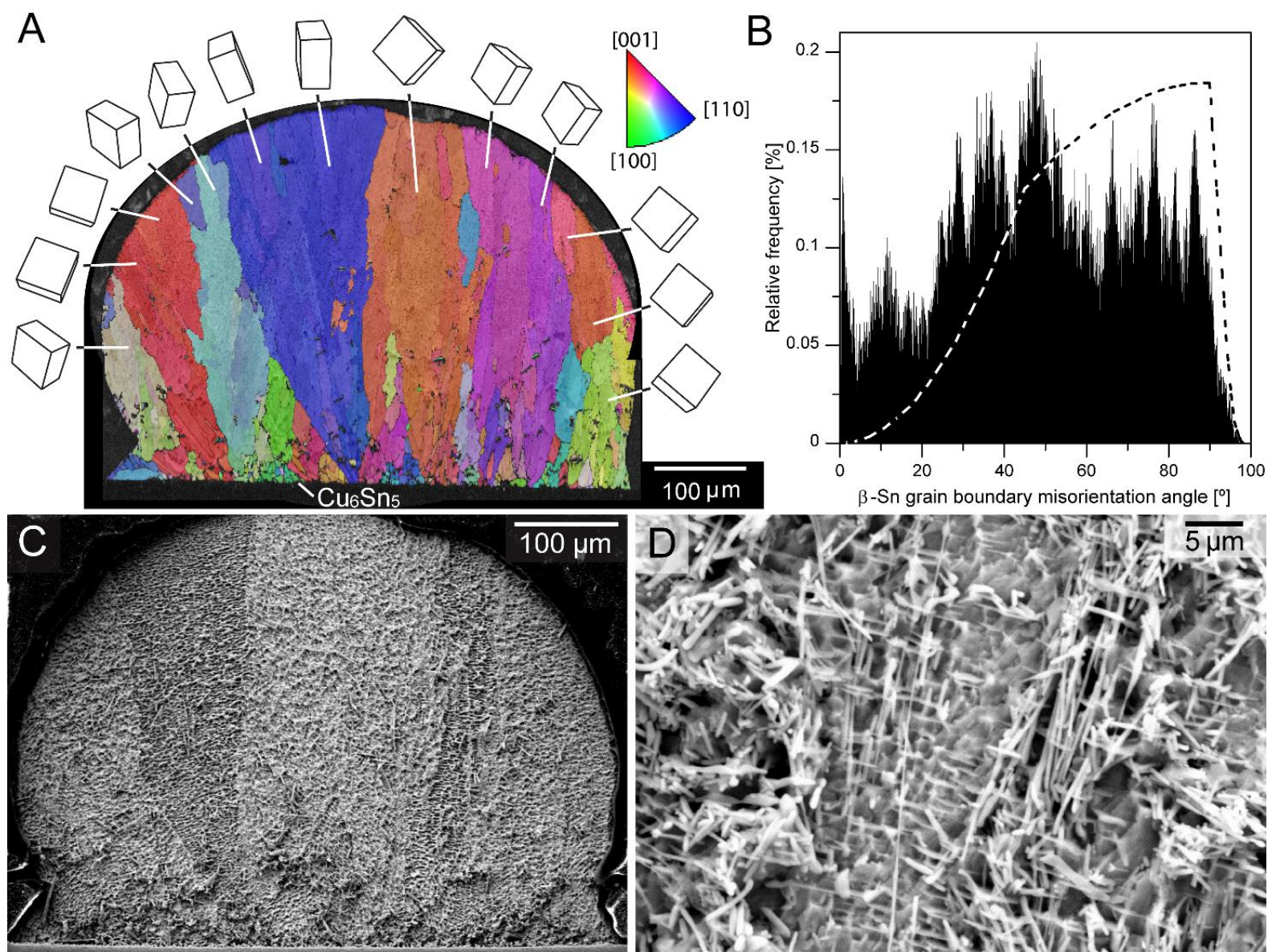

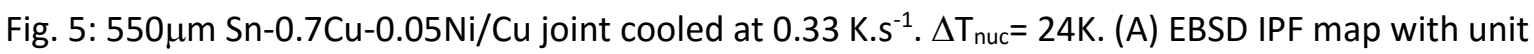
cell orientations superimposed. (B) Grain boundary misorientation histogram from the map in (A). The dashed line is the expected distribution for randomly oriented Sn grains (MacKenzie plot). (C) image after shallow etching. No dendrites are discernable. (D) higher resolution image of a typical region from (C) showing numerous $\mathrm{Cu}_{6} \mathrm{Sn}_{5}$ rods throughout a grain. 

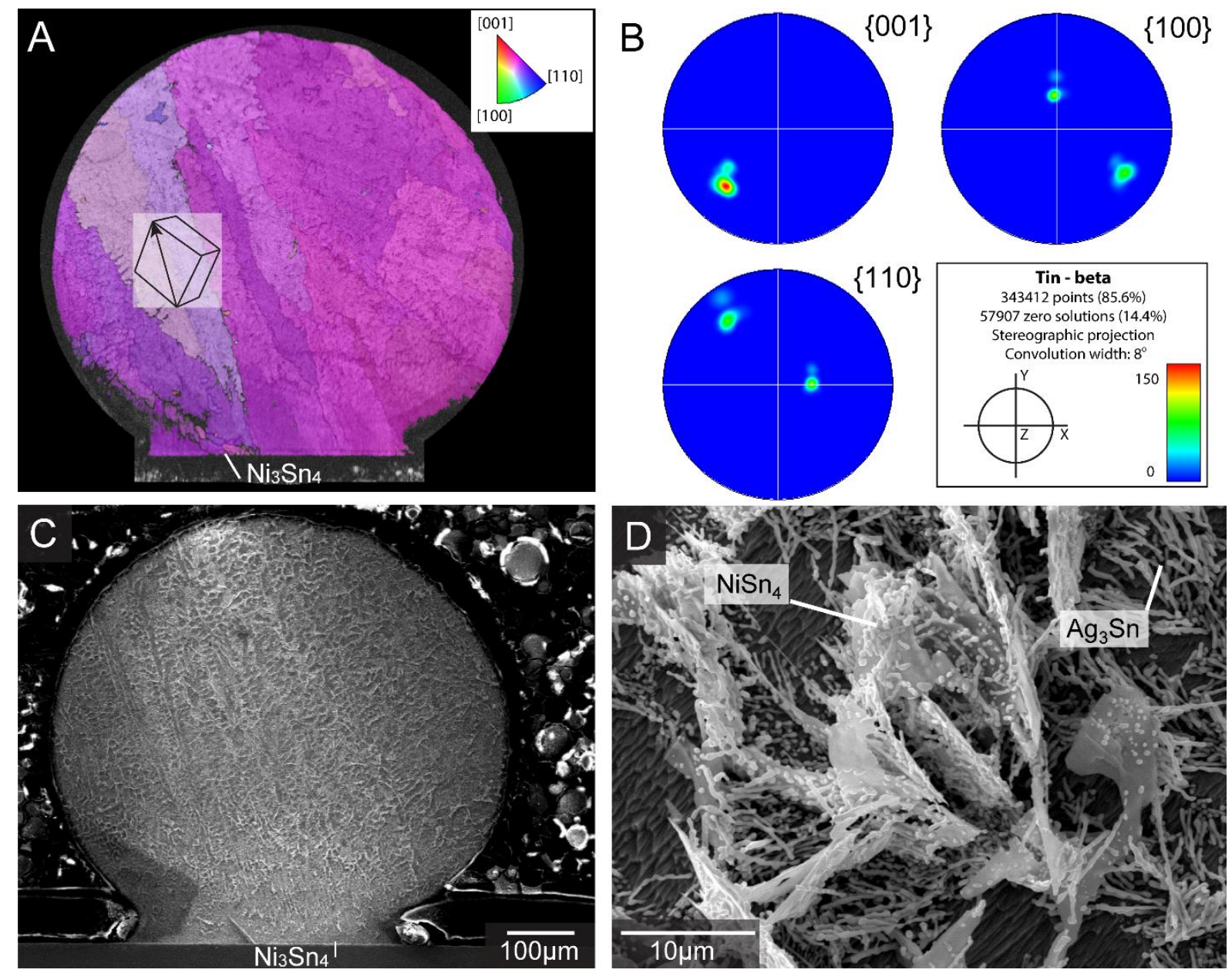

Fig. 6: $550 \mu \mathrm{m} \mathrm{Sn-3.5Ag/Ni} \mathrm{joint} \mathrm{cooled} \mathrm{at} 0.33 \mathrm{~K} \cdot \mathrm{s}^{-1} . \Delta \mathrm{T}_{\text {nuc }}=8 \mathrm{~K}$. (A) EBSD inverse pole figure map with unit cell orientation superimposed. (B) Pole figures from the map in (A). (C) image after shallow etching showing $\beta S n$ dendrites and eutectic). (D) Higher magnification image of $\mathrm{Ag}_{3} \mathrm{Sn}$ rods and metastable $\mathrm{NiSn}_{4}$ sheets in the eutectic. 


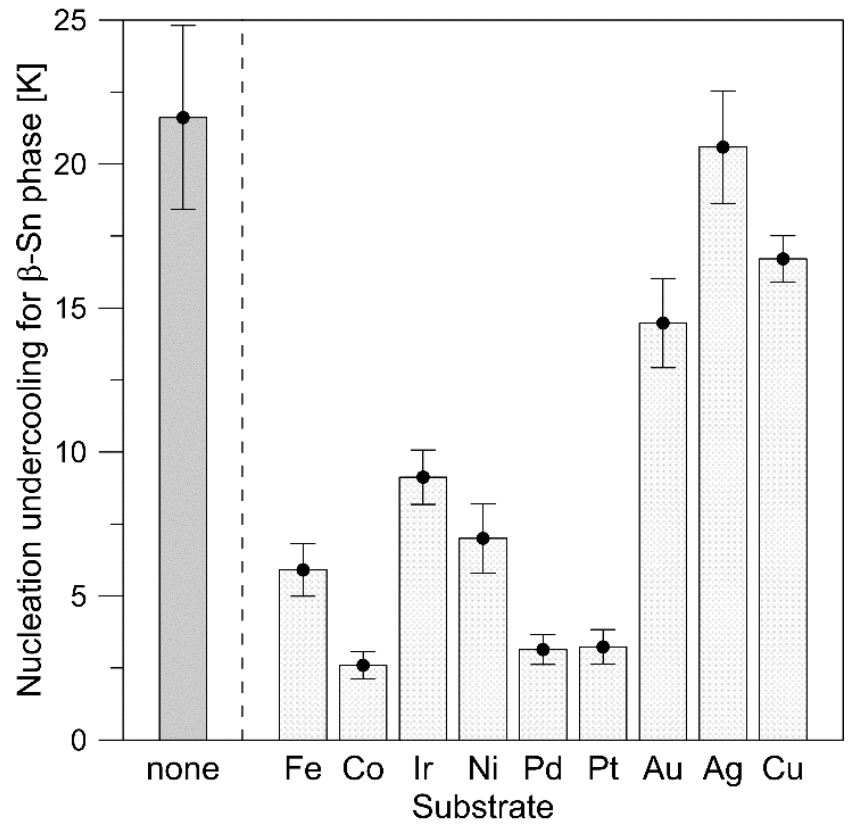

Fig. 7: Nucleation undercooling for $\beta$ Sn during soldering of $9 \mathrm{mg} 99.9 \mathrm{Sn}$ preforms to $99.9 \%$ pure metal substrates. Error bars are standard deviations from 15 measurements. 

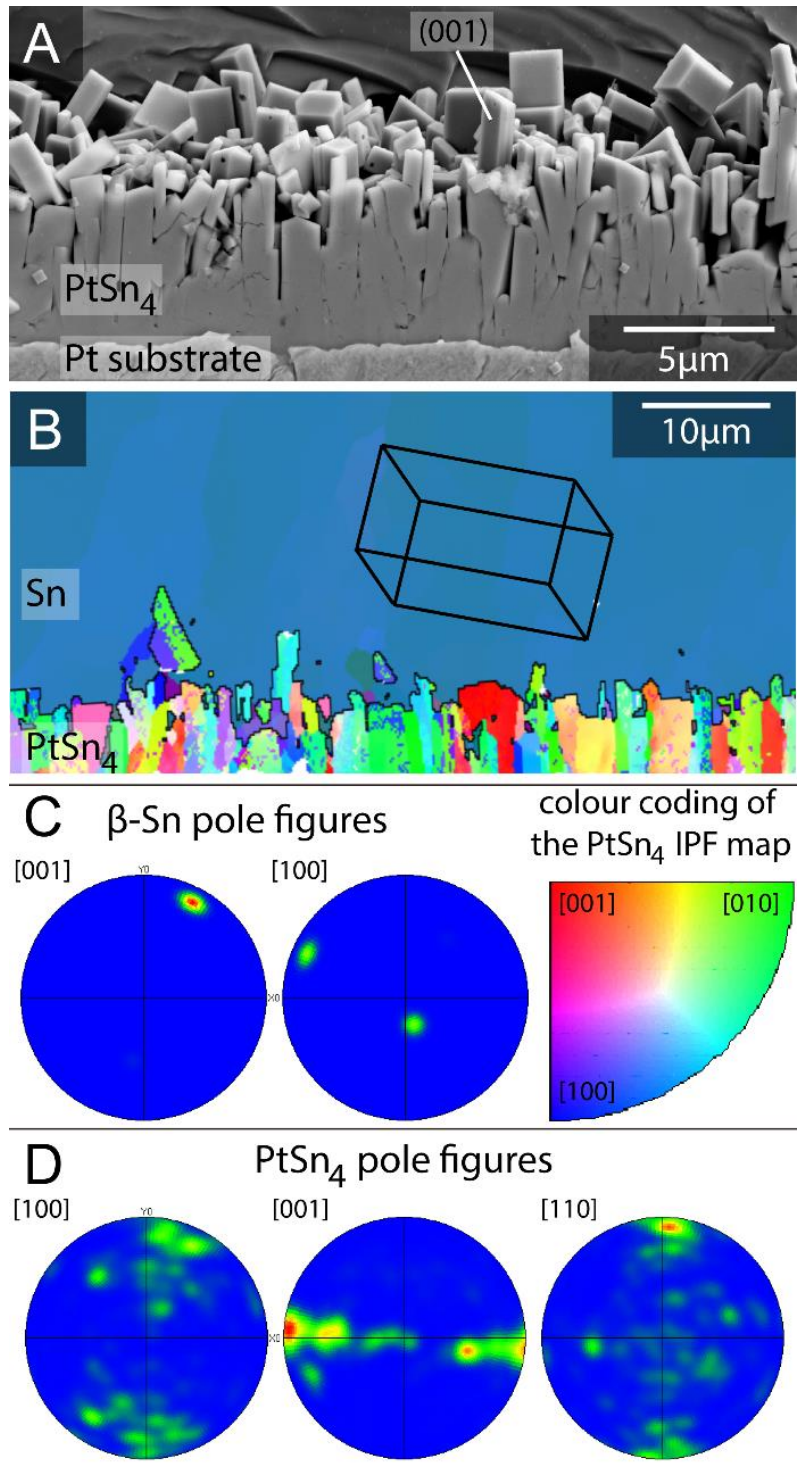

Figure 8: Typical Sn/Pt solder joint. (A) morphology of the $\mathrm{PtSn}_{4}$ reaction layer after selective dissolution of $\beta S \mathrm{Sn}$. (B) EBSD inverse pole figure (IPF) map of the $\mathrm{PtSn}_{4}$ layer and $\beta S \mathrm{~S}$. The IPF colour scale refers to orthorhombic $\mathrm{PtSn}_{4}$ The unit cell superimposed on the map refers to $\beta \mathrm{Sn}$. (C) $\beta$ Sn pole figures for the map in (B). (D) $\mathrm{PtSn}_{4}$ pole figures for the map in (B). 

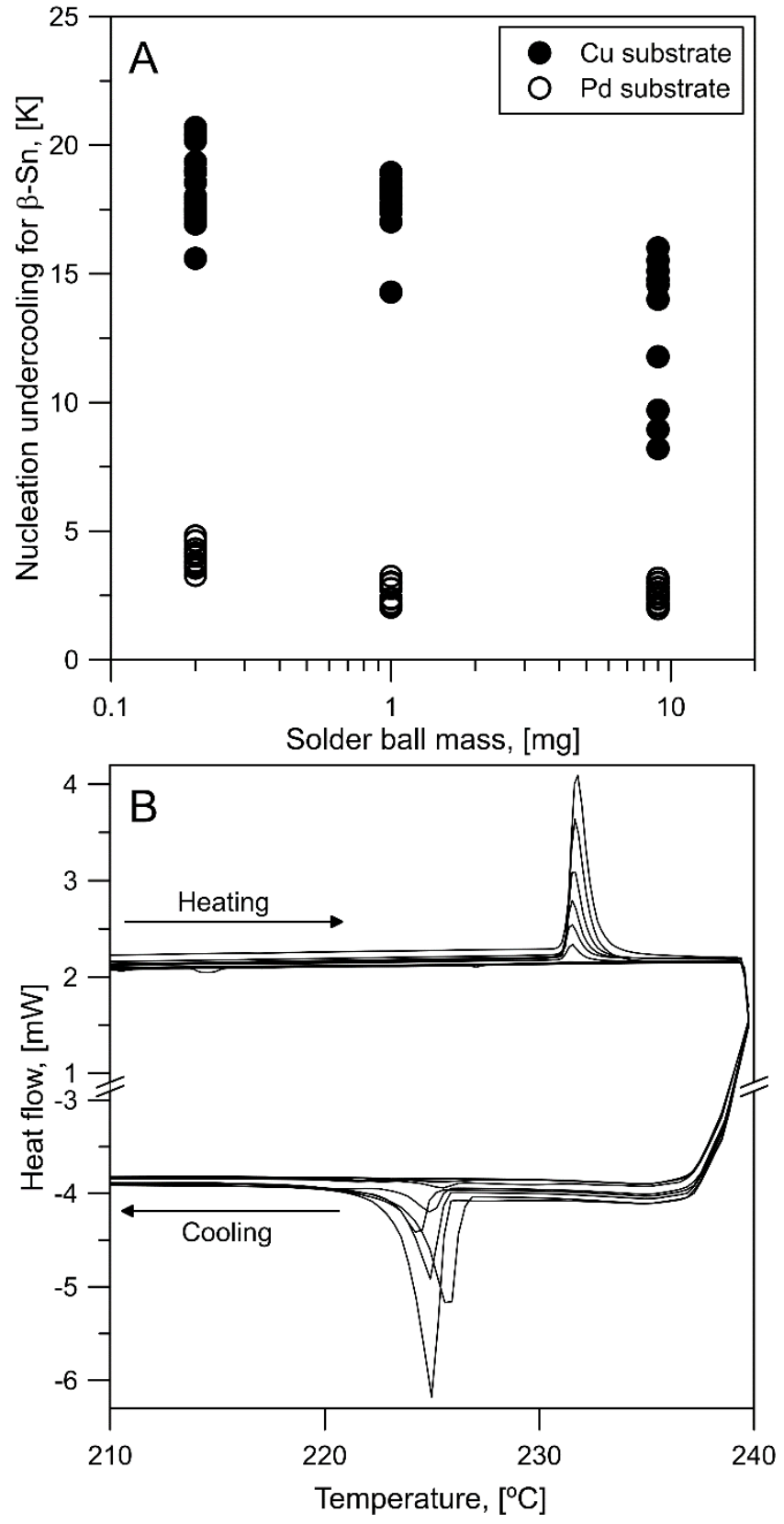

Fig. 9: (A) Nucleation undercooling versus solder mass for $\mathrm{Sn} / \mathrm{Cu}$ and $\mathrm{Sn} / \mathrm{Pd}$ solder joints. (B) DSC thermogram of 7 cycles of a $0.2 \mathrm{mg} 99.9 \% \mathrm{Sn}$ ball soldered to Pd. Note the decreasing enthalpy with each solder melting cycle. 